\title{
Influencia del tiempo de maduración en la calidad nutricional de ensilajes con forrajes arbóreos
}

\section{Influence of time of maturation in the nutritional quality of arboreal forage silage}

\author{
Roa M. L. ${ }^{1}$, Castillo C. A. ${ }^{2}$, Téllez E. ${ }^{2}$, \\ 'Zootecnista, MSc. Docente Universidad de los Llanos, y \\ ${ }^{2}$ MVZ Universidad de los Llanos \\ mroa@unillanos.edu.co
}

Recibido 09 de Noviembre de 2009, aprobado 01 de Diciembre 2010

\section{RESUMEN}

Este trabajo se realizó en la Universidad de los Llanos ubicada en el Km 12 vía Puerto López en la Vereda Barcelona, Departamento Meta, Colombia. Se evaluó la calidad nutricional de ensilajes de cuatro especies forrajeras preparados con las siguientes especies: veranera (Cratylia argéntea), Cayeno (Hibiscus-rosa-sinensis) nacedero (Trychanthera gigantea) y Botón de oro (Titonia diversifolia). Las especies se sembraron en parcelas, y después se realizó una poda y 60 días después se cosecharon sus hojas las cuales fueron conservadas en microsilos de 5 kilogramos, dejando cuatro periodos de maduración (0, 30, 60, 90 días). Los ensilajes fueron analizados en el Laboratorio de Nutrición Animal: materia seca (MS), cenizas, grasa, proteína, fibra cruda (FC), fibra detergente neutro (FDN), fibra detergente ácido (FDA), nitrógeno adherido a FDN (NFDN), celulosa, y lignina. La especie que más materia seca produjo fue la veranera $32.6 \%$ seguida de botón de oro $(30 \%)$, cayeno $(28,5 \%)$ nacedero $(25 \%)$. Aunque se observó un aumento de la MS a medida que aumentaba el tiempo de maduración del ensilaje $(0,30,60$ y 90). También se mostraron incrementos a medida que el forraje maduraba la FDN, FDA y la lignina en estas cuatro especies forrajeras. El porcentaje de proteína en las cuatro especies decreció con mayor tiempo de maduración del ensilaje de estas forrajeras, esta reducción fue mayor en la veranera $(8.2 \%)$ en comparación con las demás: cayeno $(6 \%)$, cajeto $(6 \%)$ y botón de oro $(4 \%)$. 
Palabras claves: Arbóreas, conservación, contenido de nutrientes.

\begin{abstract}
This work was conducted at the Universidad de los Llanos located on the Barcelona hamlet, Meta Department, Colombia. In this investigation was evaluated the nutritional quality of silages prepared with forage trees: Cratylia argentea, Hibiscus rosa-sinensis, Trychanthera gigantea and Tithonia diversifolia. The species were sown in plots, and then made a pruning and were harvested 60 days after which leaves were kept silages $5 \mathrm{~kg}$, leaving four periods of maturation $(0,30,60,90$ days). The silage was analyzed in the Laboratory of Animal Nutrition: dry matter (DM), ash, fat, protein, crude fiber (CF), neutral detergent fiber (NDF), acid detergent fiber (ADF), nitrogen joined FDN (NFDN), cellulose, and lignin. Cratylia, argentea (32.6\%) was produced more dry matter than Tithonia diversifolia (30\%), Hibiscus rosa-sinensis (28.5\%) and Trychanthera gigantea (25\%). Although there was an increase of DM with increasing the retention period of silage $(0,30,60$ and 90) as increases FDN, FDA and lignin in these four forage species too. The protein in the four species decreased with longer maturity of these forage silage, this reduction was greater in Cratylia argentea (8.2\%) compared with others: Hibiscus rosasinensis (6\%), Trychanthera gigantea (6\%) and Tithonia diversifolia (4\%).
\end{abstract}

Keywords: Trees, conservation, nutrient content.

\title{
INTRODUCCIÓN
}

El principal objetivo de este trabajo fue evaluar la calidad nutricional de ensilajes preparados con las siguientes especies: Veranera (Cratylia argéntea), cayeno (Hibiscus-rosa-sinensis) cajeto (Trychanthera gigantea), y botón de oro (Titonia diversifolia), con el fin de dotar de herramientas técnicas a los productores de la región en sistemas de suplementación, utilizando estas cuatro especies forrajeras que pueden ser productivas en la región del piedemonte llanero (Roa et al., 2002). 
En Colombia, en la zona del piedemonte llanero se presentan épocas de lluvia y sequía, esta última es la que representa el mayor problema debido a la disminución en la calidad y disponibilidad de forraje. La conservación de especies de alta producción por unidad de área, a través de él ensilaje representa una alternativa para asegurar el suministro permanente de alimento en las cantidades requeridas por el animal. Los árboles forrajeros en su mayoría tienen buena aceptación y calidad nutricional para los animales, hay excepciones, no por su calidad como alimento sino por su palatabilidad Roa et al., (1999) reportan que cuando se ofrece el cayeno fresco se incrementa el consumo adicionando jugo de caña $u$ oreando sus hojas, determinando que los animales pueden consumir hasta en un $4 \%$ de materia fresca con relación al peso vivo, por lo tanto se viene generado múltiples investigaciones utilizando arboles forrajeros con el fin de aprovechar su excelente adaptación y calidad biomasa.

Con relación a la composición nutricional se ha reportado por varios autores que el contenido de proteína, fibra detergente neutro y fibra detergente ácido, fue para: Veranera (20.8, 57.2 y $36.1 \%)$, cayeno (13.8, 35.8 y $23 \%$ ), nacedero o cajeto $(19.2,42.0$ y $27.0 \%)$ y botón de oro (24.2, 35.3 y $30.4 \%)$, respectivamente.

\section{MATERIALES Y MÉTODOS}

Las parcelas donde se establecieron estas cuatro especies forrajeras del estudio se encuentran en la Universidad de los Llanos ubicada en el Km 12 vía Puerto López en la Vereda Barcelona, con una altitud de 465 metros sobre el nivel del mar, temperatura de 27 grados centígrados y precipitación anual entre 1900 y 3250 milímetros. Las plantas, se dejaron crecer durante seis meses, tiempo en el cual se realizó una poda y luego se dejó un tiempo de recuperación, realizando el primer corte de estas cuatro especies a los 60 días. Con este material se prepararon microsilos de 3 kilogramos con tiempo de maduración: cero (0), 30, 60 y 90 días, a los cuales se les determinó en el laboratorio de Nutrición Animal: materia seca (MS), cenizas, grasa, proteína, 
fibra cruda (FC), fibra detergente neutro (FDN), fibra detergente ácido (FDA), nitrógeno adherido a FDN (NFDN), celulosa, y lignina. (AOAC, 2006).

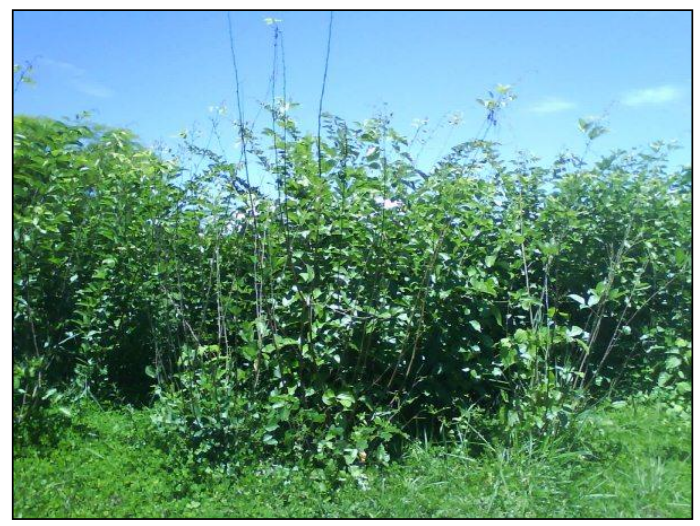

Se realizó mantenimiento de las parcelas, limpiando con azadón para retirar malezas de los forrajes establecidos e incluidos en el presente estudio cada 30 días, se aplicó cal y abono triple 15 en el momento de la siembra

Se recolectó el forraje y se picó la materia verde para la elaboración del ensilaje.
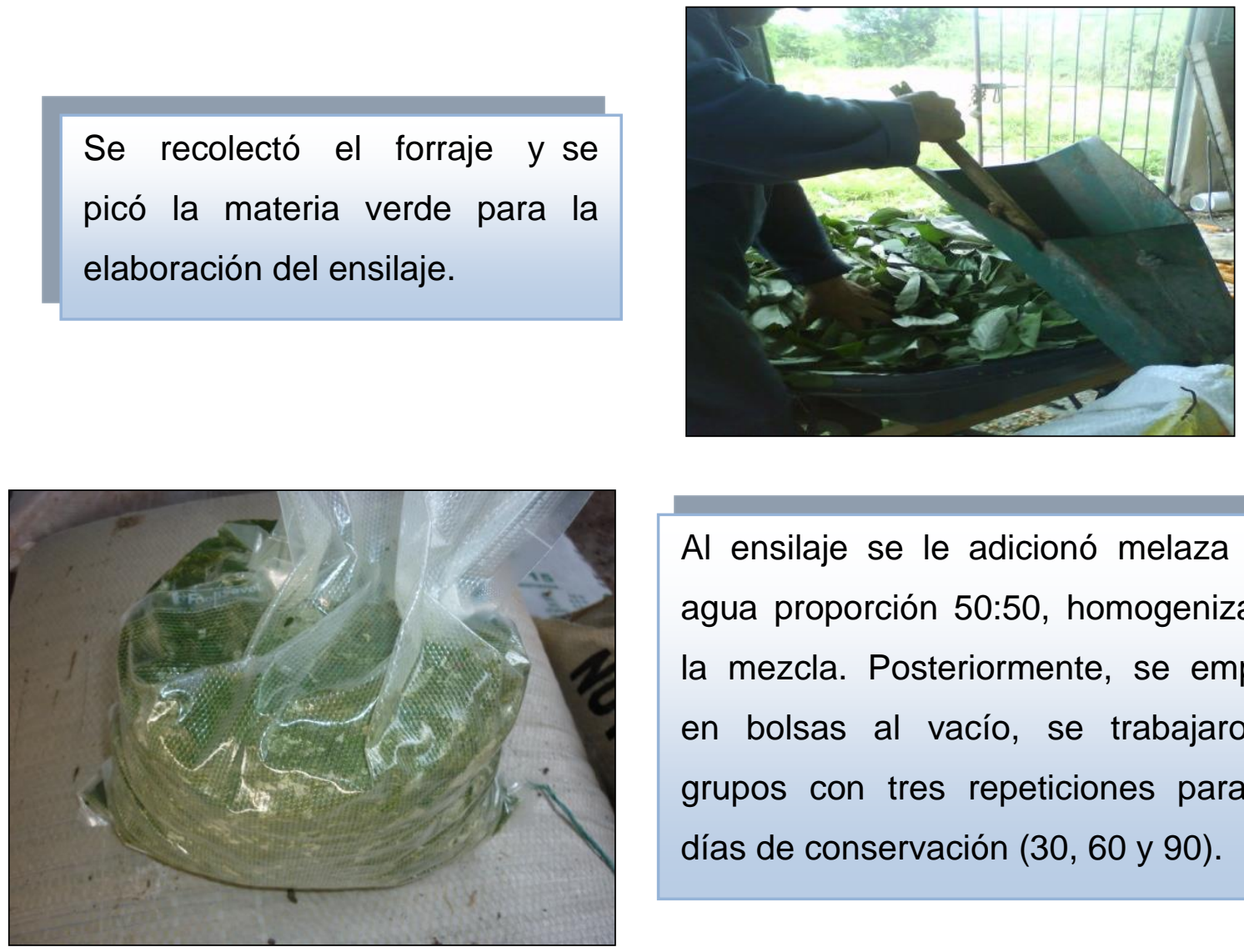

Al ensilaje se le adicionó melaza más agua proporción 50:50, homogenizando la mezcla. Posteriormente, se empacó en bolsas al vacío, se trabajaron 3 grupos con tres repeticiones para los días de conservación (30, 60 y 90).

\section{RESULTADOS Y DISCUSIÓN}

El contenido de materia seca no presentó variación con los diferentes tiempos de maduración (0,30,60, 90 días) del ensilaje (Gráfica 1) siendo más alto el porcentaje promedio de la MS en la veranera (32.6\%) en comparación 
con las demás especies (30, 28.5 y $25.8 \%)$, botón de oro, cayeno y nacedero, respectivamente (Tablas 1, 2, 3 y 4).

Tabla 1. Composición nutricional (\%) de las cuatro forrajeras a los 60 días corte, sin ensilar

\begin{tabular}{lcccc}
\hline \multicolumn{1}{c}{ Nutrientes } & Veranera & Cayeno & Nacedero & Botón de oro \\
\hline Materia seca & 32.0 & 24.7 & 21.0 & 28.6 \\
Cenizas & 8.3 & 9.5 & 10.1 & 9.4 \\
Grasa & 1.9 & 1.8 & 1.4 & 3.8 \\
Proteína & 17.2 & 13.8 & 18.3 & 10.0 \\
Fibra cruda & 16.5 & 11.1 & 19.7 & 31.6 \\
FDN & 47.0 & 20.4 & 27,9 & 39.4 \\
FDA & 39.4 & 17.4 & 22.1 & 29.7 \\
NFDN & 1 & 1.2 & 1.2 & 1.5 \\
Celulosa & 18.0 & 2.2 & 10.4 & 11.1 \\
Lignina & 9.6 & 1.9 & 2.5 & 6.2 \\
\hline
\end{tabular}

FDN= Fibra detergente neutro, FDA= Fibra detergente ácido, Nitrógeno adherido a NFDN.

En la determinación de la MS de los ensilajes se resalta que en los diferentes días de maduración $(0,60,90,120$ días) la Veranera Cratylia argéntea es el forraje con mayor rendimiento de MS, comparado con los otros forrajes, siendo el nacedero el de menor MS (Gráfica 1). Por lo cual se muestra que a mayor tiempo de maduración la MS se incrementa en todas las especies.

Los análisis nutricionales del ensilaje recién preparado (Tabla1) muestran que el nacedero es la especie que contiene mayor proteína 1.1, 4.5 y 8.3\%, comparación con veranera, cayeno y botón de oro, respectivamente, mientras que los porcentajes de FDN y lignina fueron superiores en veranera en comparación con las otras tres especies, siendo la de menor contenido el cayeno.

El porcentaje de proteína se disminuyó a los días 30 de maduración del ensilaje para: veranera $5.7 \%$, cayeno $2.9 \%$, nacedero $1.8 \%$ y botón de oro $2 \%$ (Tablas 1, 2, 3, 4 y Gráfica 2). Lo mismo sucedió en los 60 días de maduración se redujo este nutriente en comparación con el día cero (sin ensilar) para: veranera $6.8 \%$, cayeno $3.7 \%$, nacedero $6.3 \%$ y botón de oro $2.8 \%$ Igual, a los 
90 días el porcentaje de proteína descendió en comparación con el día cero: veranera $8.2 \%$, cayeno $6 \%$, nacedero $6 \%$ y botón de oro $4 \%$. El contenido de proteína de las hojas de veranera y nacedero (17.2\% y $18 \%$ respectivamente) al cero día, fueron similares a los encontrados por Franco et al., (2000) y Murgueitio y Preston, (1987) los cuales fueron de $17.9 \%$ y $18 \%$ de proteína bruta, respectivamente.

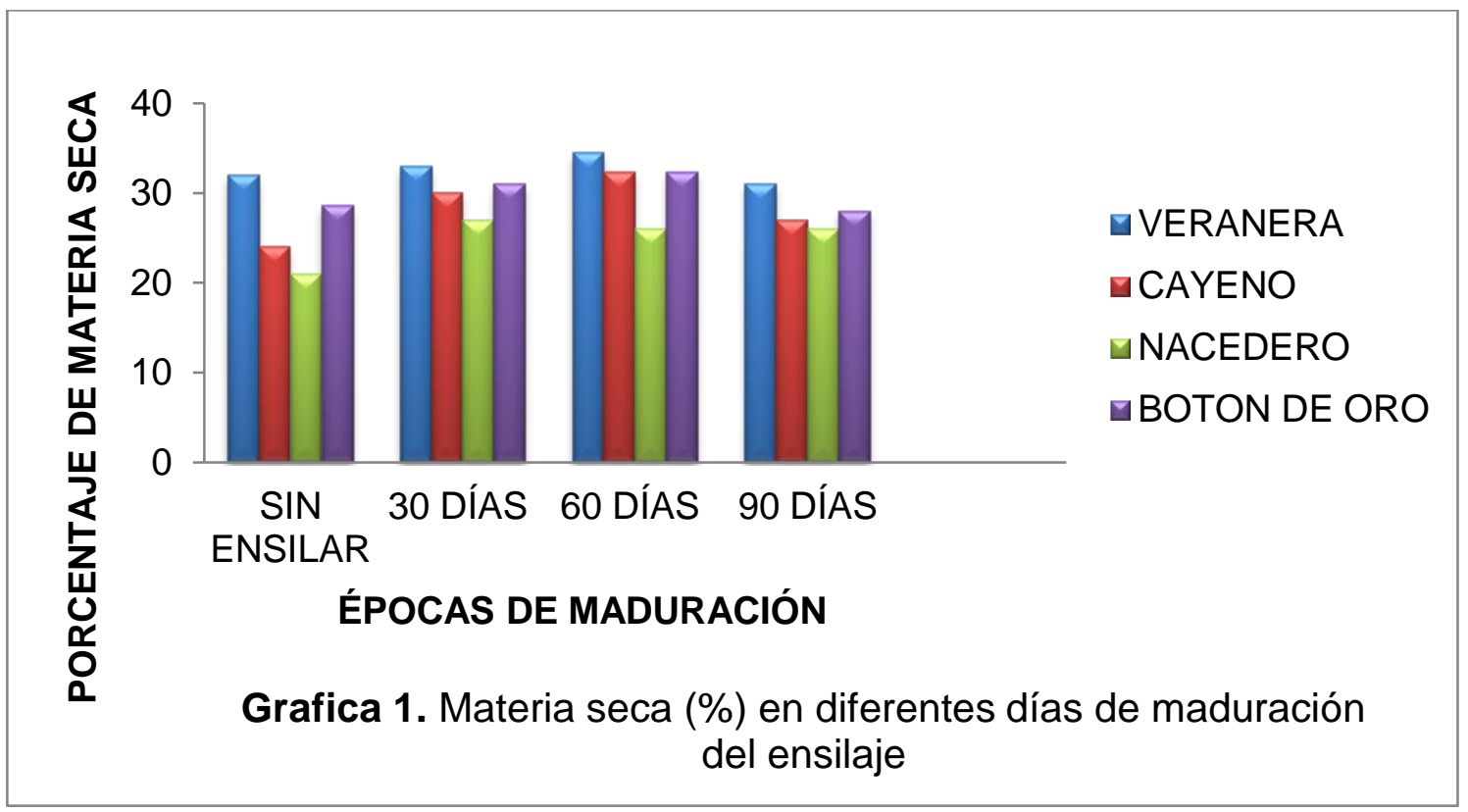

Tabla 2. Composición nutricional (\%) de las cuatro forrajeras a los 60 días corte y 30 días de maduración del ensilaje

\begin{tabular}{lcccc}
\hline Nutrientes & Veranera & Cayeno & Nacedero & Botón de oro \\
\hline Materia seca & 33.3 & 29.6 & 27.1 & 30.5 \\
Cenizas & 9.2 & 12.1 & 12.3 & 8.5 \\
Grasa & 1.9 & 1.8 & 1.6 & 1.7 \\
Proteína & 11.5 & 10.9 & 16.5 & 8.0 \\
NFDN & 1.1 & 0.7 & 2.3 & 1.1 \\
Fibra cruda & 18 & 15.1 & 13.9 & 32.4 \\
FDN & 48.0 & 23.9 & 34.0 & 49.7 \\
FDA & 28.7 & 15.5 & 23.0 & 27.0 \\
Celulosa & 19.0 & 2.3 & 18.4 & 14.7 \\
Lignina & 10.0 & 4.8 & 3.1 & 8.7 \\
\hline
\end{tabular}

FDN= Fibra detergente neutro, FDA= Fibra detergente ácido, Nitrógeno adherido a NFDN. 


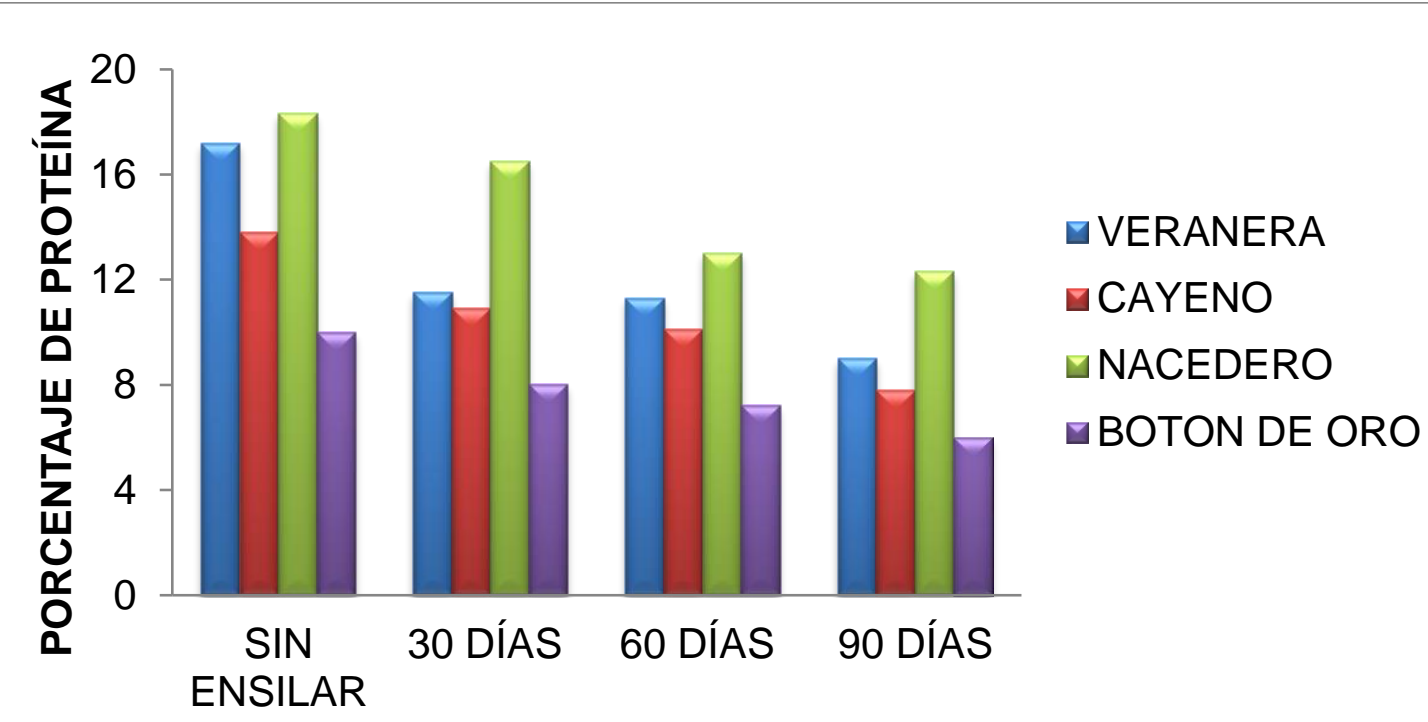

TIEMPO DE MADURACIÓN

Gráfica 2. Proteína (\%) en diferentes días de maduración del ensilaje

El contenido de FDN se incrementó cuando se fueron madurando los ensilajes (30, 60 y 90 días) comparándolos con el día cero se incrementaron los porcentajes respectivamente en: veranera (1\%, $4 \%$ y $5 \%)$, cayeno $(3.5 \%$, $19.7 \%$ y $20.4 \%)$, cajeto $(6.1 \%, 14.1 \%, 14.9 \%)$ y botón de oro $(10.3 \%, 15.1 \%$ y 15.7\%) (Tablas 1, 2, 3, 4 y Gráfica 3).

Tabla 3. Composición nutricional (\%) de las cuatro forrajeras a los 60 días corte y 60 días de maduración del ensilaje

\begin{tabular}{lcccc}
\hline Nutrientes & Veranera & Cayeno & Nacedero & Botón de oro \\
\hline Materia seca & 34.4 & 32.3 & 28.3 & 32.4 \\
Cenizas & 7.5 & 12.7 & 15.8 & 10.1 \\
Grasa & 2.1 & 1.5 & 0.7 & 0.6 \\
Proteína & 11.3 & 10.1 & 13.0 & 7.2 \\
Fibra cruda & 18.8 & 10.3 & 17.1 & 35.6 \\
FDN & 52.0 & 40.1 & 42.0 & 55.1 \\
FDA & 20.2 & 15.1 & 31.7 & 37.7 \\
NFDN & 1.5 & 0.8 & 1.4 & 1.2 \\
Celulosa & 13.1 & 15.6 & 12.6 & 12.0 \\
Lignina & 15.0 & 4.9 & 5.3 & 12.8 \\
\hline
\end{tabular}

FDN= Fibra detergente neutro, FDA= Fibra detergente ácido, Nitrógeno adherido a NFDN. 
La lignina al igual que la FDN se aumentó, a medida que se maduraba el ensilaje (30,60, 90 días) con relación al día cero, el incrementó respectivo fue para: veranera $(0.4 \%, 5.4 \%$ y $6.2 \%)$, cayeno $(2.9 \%, 3 \%$ y $1 \%)$, nacedero $(0,6 \%, 2.8 \%$ y $10.4 \%)$ y botón de oro $(2,5 \%, 6.6 \%$ y $7.2 \%)$ (Tablas $1,2,3,4$ y Gráfica 4).

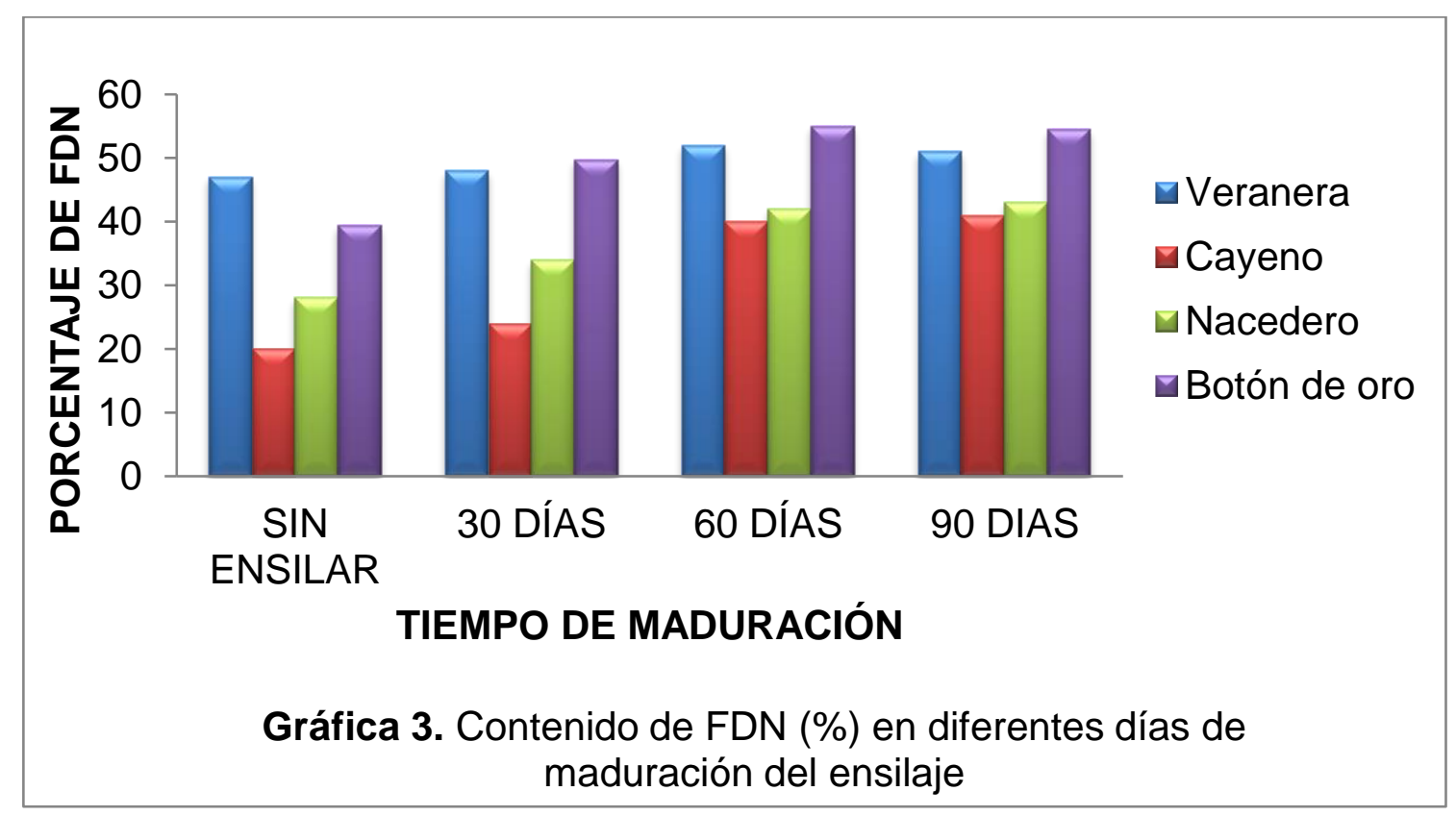

Tabla 4. Composición nutricional (\%) de las cuatro forrajeras a los 60 días corte y 90 días de maduración del ensilaje

\begin{tabular}{ccccc}
\hline Nutrientes & Veranera & Cayeno & Nacedero & Botón de oro \\
\hline Materia seca & 30.8 & 27.4 & 26.8 & 28.1 \\
Cenizas & 9.0 & 13.2 & 17.4 & 13.2 \\
Grasa & 1.8 & 3.4 & 3.2 & 1.3 \\
Proteína & 9.0 & 7.8 & 12.3 & 6.0 \\
NFDN & 1.9 & 1.2 & 1.8 & 2.3 \\
Fibra cruda & 23.1 & 10.9 & 18.3 & 35.4 \\
FDN & 51.0 & 40.8 & 42.8 & 54.5 \\
FDA & 20.0 & 15.1 & 29.6 & 31.2 \\
Celulosa & 12.5 & 16.0 & 5.7 & 12.4 \\
Lignina & 15.8 & 5.9 & 12.9 & 13.4 \\
\hline
\end{tabular}

FDN= Fibra detergente neutro, FDA= Fibra detergente ácido, Nitrógeno adherido a NFDN. 
Los resultados de la FDN (47\%) y FDA (39.4\%) de la veranera encontrados en este trabajo fueron mayores a los obtenidos por Franco et al., (2000) que cuando las hojas de veranera se trataron con melaza, el valor promedio de $45.2 \%$ de FDN y de $29.8 \%$ de FDA (Tabla1), dichos valores, al ser comparados con los del forraje sin adición de melaza, fueron inferiores en 5.8 y $4.1 \%$ para FDN y FDA respectivamente.

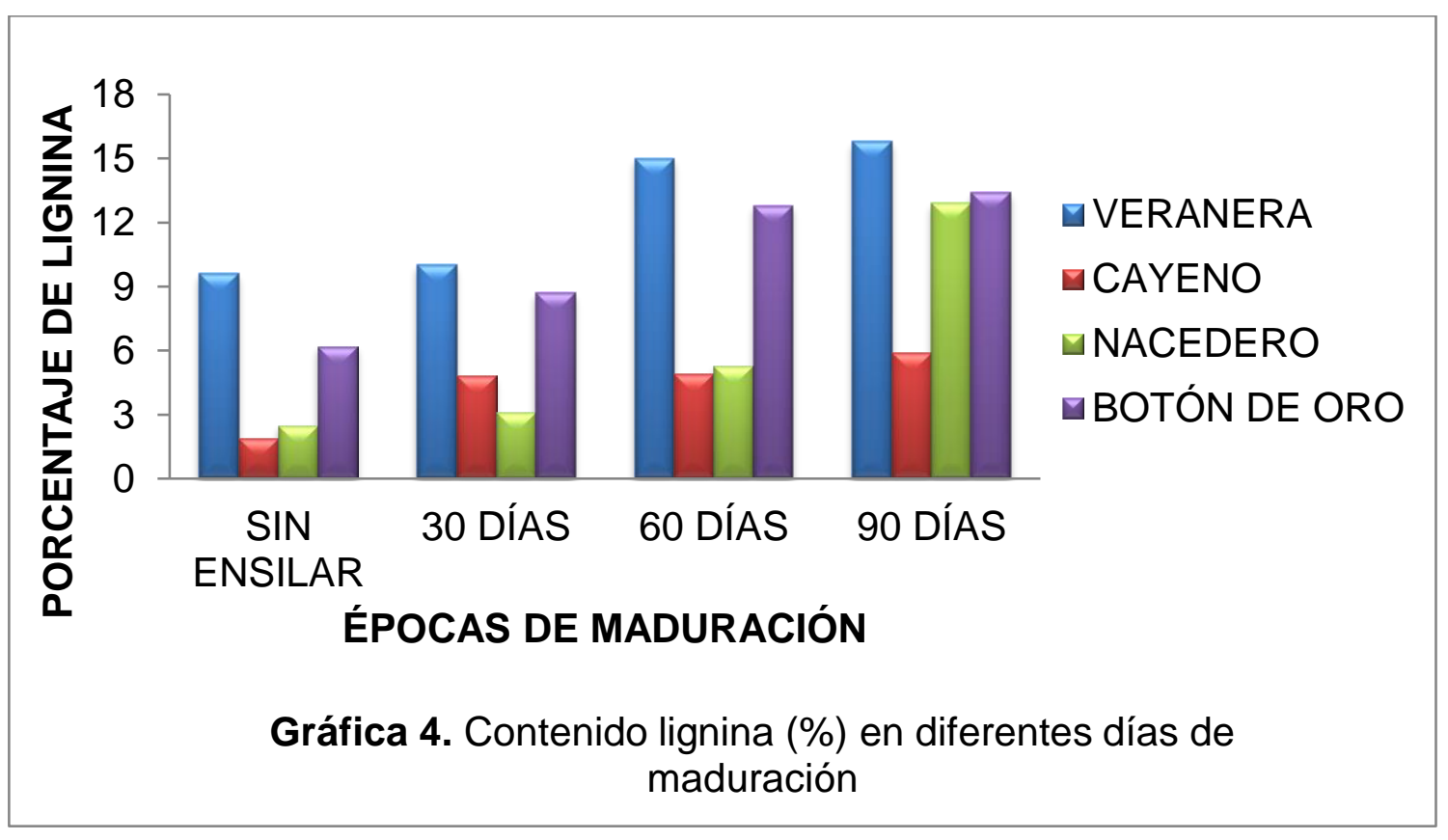

Los valores de la FDN (27.9\%) y FDA (22.1\%) fueron más bajos que los encontrados por Hess y Domínguez, (2000) quienes reportaron $41.9 \%$ y $37.8 \%$, respectivamente. Estas diferencias tan altas pueden estar influenciadas por el tipo y tratamiento del suelo. No sucedió igual con el botón de oro cuyo resultado de la FDN fue $39.4 \%$, mientras que el porcentaje de FDN analizado por Mahecha y Rosales, (2005) fue de 37.5\%.

\section{CONCLUSIONES}

La especie que más materia seca produjo fue la veranera $32.6 \%$ seguida de botón de oro $(30 \%)$, cayeno $(28,5 \%)$ nacedero $(25 \%)$. Aunque se observó un aumento de la MS a medida que aumentaba el tiempo de maduración del ensilaje $(0,30,60$ y 90). También se mostraron incrementos en la FDN, FDA y 
la lignina a medida que el forraje maduraba, en estas cuatro especies forrajeras.

El porcentaje de proteína en las cuatro especies decreció con mayor tiempo de maduración del ensilaje de estas forrajeras, esta reducción fue mayor en la veranera (8.2\%) en comparación con las demás: cayeno (6\%), cajeto $(6 \%)$ y botón de oro (4\%).

Son pocas las experiencias que se reportan en la literatura, ensilando arbóreas forrajeras, por lo tanto, se recomienda realizar más estudios con el fin de profundizar en el tema, puesto que Colombia es un país que tiene dos épocas (invierno y sequía), y cuando estas condiciones climáticas son drásticas es necesario tener alternativas para la conservación de forrajes y así suplir de forma adecuada al ganado en dichos periodos.

\section{REFERENCIAS BIBLIOGRÁFICAS}

1. AOAC. Official Methods of Analysis (18 $\left.{ }^{\text {th }}\right)$ Association of Official Analytical Chemists, Arligton, VA. Washington, D.C. 2006

2. Aparicio R., Lascano C., Avila P. Utilización de la Cratylia argentea madura y joven como banco de proteína por vacas de leche. Revista Científica Vol. XIISuplemento 2, Octubre, 595 - 598. 2002.

3. Flores O., Bolivar D., Botero R., Ibrahim M. A. Parámetros nutricionales de algunas arbóreas leguminosas y no leguminosas con potencial forrajera para la suplementación de rumiantes en el trópico. Centro Agronómico Tropical De Investigación Y Enseñanza, Turrialba, Costa Rica. 2001.

4. Franco V., Ibrahim M. H., Muhamad C. A. Calidad nutricional de Cratylia argentea como suplemento en el sistema de producción doble propósito en el trópico subhúmedo de Costa Rica. Resúmenes: Ier Congreso Latinoamericano sobre Agroforestería para la Producción Agrícola Sostenible. Cali, Colombia. p 57.25 a 27 de Octubre de 1999.

5. Hess H. D., Domínguez J. C. Follaje de nacedero (Trichanthera gigantea) como suplemento en la alimentación del ovino. Rev. Pasturas Trópicales. Vol 20 No 3. p 11-15. 2000. Disponible En: http://ciat-library.ciat.cgiar.org/Articulos _Ciat/PAST2032.pdf. 
6. Mahecha L. Valor nutricional del botón de oro (Tithonia diversifolia) en la alimentación animal. En: tres especies vegetales promisorias- CIPAV- Cali, Colombia. p 211 - 236. 2002.

7. Niño M., Roa Z. Evaluación nutricional de tres especies de árboles forrajeros: morera (Morus alba), matarraton (Gliricidia sepium) y nacedero (Trichanthera gigantea) en bovinos fistulados. Rev. Sist. Agroecológicos, Vol. (1): 19 - 34. 2009.

8. Ríos C. Usos y manejo y producción de botón de oro (Tithonia diversifolia). En: tres especies vegetales promisorias. CIPAV, Cali, Colombia. p. $211-236$. 2002.

9. Roa M. L., Céspedes D., Muñoz J. Evaluación Nutricional de tres especies de árboles forrajeros en bovinos fistulados en el pie de monte Llanero. Revista ACOVEZ, Vol. 24 N 2: 14 - 18. Edición 84, Junio de 1999.

10. Roa M. L., Muñoz H. R., Galeano J.R., Céspedes D. A. Suplementación alimenticia de vacas de doble propósito con morera (Morus alba), Nacedero (Trichanthera gigantea) y pasto kinggrass (Pennisetum purpureum $\mathrm{x}$ Pennisetum typhoides) en el pie de monte llanero, Colombia Rev Agroforestería Américas Vol. 7 (28) p. 8 - 11. 2000.

11. Roa M. L., Galeano J., Muñoz J. Suplementación de vacas doble propósito con Morus alba y Erythrina glauca en época seca en la subregión del pie de monte llanero Colombia. Rev. Orinoquia, Vol. 6, Fasc: págs: 70 - 87. 2002.

12. Roa M. L. Contenido nutricional de forraje y alimentos para animales. Universidad de los Llanos. Escuela Medicina Veterinaria y Zootecnia. Villavicencio, Colombia P. 38 - 54. 2004.

13. Ruiz D., Lara P., Sierra A., Aguilar E., Magaña M., Sanginés J. Evaluación nutritiva y productiva de ovinos alimentados con heno de Hibiscus rosasinensis. Zootecnia Trop., 24 (4): 467 - 482. 2006.

14. Sarria P. Forrajes arbóreos en la alimentación de monogástricos. En: Agroforestería para la Producción Animal en América Latina (II Conferencia Electrónica). FAO/CIPAV. Roma. 2000. Disponible En: http://www.cipav.org.co, accedido el 15 de enero de 2004. 